American Journal of Pharmaceutical Education 2020; 84 (9) Article 7808.

\title{
RESEARCH
}

\section{The Impact of Hurricane Maria on Student Pharmacists and Their Perception of Their Academic Performance}

\author{
Georgina Silva-Suarez, PhD, ${ }^{a}$ Yarelis Alvarado Reyes, PharmD, ${ }^{\text {a }}$ Linnette Rodriguez-Figueroa, $\mathrm{PhD},{ }^{\mathrm{b}}$

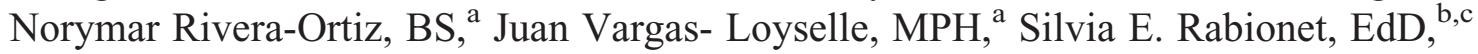 \\ Patricia Medina, PharmD, ${ }^{a}$ Raquel Lozada, PharmD, ${ }^{a}$ Blanca Ortiz, PharmD ${ }^{\mathrm{a}}$

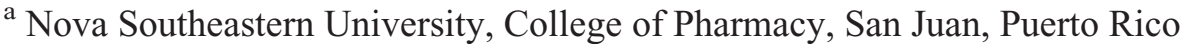 \\ ${ }^{\mathrm{b}}$ University of Puerto Rico, Medical Sciences Campus School of Public Health, San Juan, Puerto Rico \\ ${ }^{c}$ Nova Southeastern University, College of Pharmacy, Davie, Florida \\ Submitted August 5, 2019; accepted February 25, 2020; published September 2020.
}

Objective. To assess the self-reported impact of hurricane Maria on the perceived academic performance of student pharmacists at Nova Southeastern University's (NSU) Puerto Rico Regional Campus. Methods. A 37-item electronic instrument, the Hurricane Impact Survey, was created and sent by email to all student pharmacists $\geq 21$ years old enrolled at NSU-COP Puerto Rico Campus during the fall 2017 semester. The electronic survey was available through Redcap platform for four weeks. Descriptive statistics, bivariate analysis, and logistic regression were used to analyze students' responses. Qualitative analysis was used to identify emerging themes in the open-ended comments.

Results. A total of 150 student pharmacists completed the survey for a response rate of $69 \%(150 / 215)$. More than $70 \%$ of student pharmacists perceived that their academic performance was affected after the hurricane. About one third of students reported not being able to function mentally at the same level as they had prior to the storm $(n=53,35 \%)$ and reported having difficulty sleeping $(n=54,36 \%)$. Female student pharmacists were more likely than male student pharmacists to report not being able to function at the same level mentally as they had before the hurricane (41\% vs $17 \%)$. In the multivariate analysis, first- and second-year student pharmacists were more likely to perceive a negative impact on their academic performance compared to third- and fourth-year student pharmacists. Lack of preparedness, gratefulness, and campus management were the themes that emerged from the qualitative analysis. Conclusion. Hurricane Maria had a significant impact on the lives of student pharmacists in Puerto Rico. This led to a perception of diminished academic performance, especially among first- and second-year students. The results can be used to guide preparedness and response to natural disasters in academic settings.

Keywords: Hurricane Maria, pharmacy school, students, Puerto Rico, academic performance

\section{INTRODUCTION}

Hurricane Maria made landfall in Puerto Rico in September 2017 and the resulting damage was unprecedented. Puerto Rico had not faced a storm with sustained winds of $155 \mathrm{mph}$ since $1928 .^{1,2}$ Hurricane Maria is considered one of the costliest hurricanes in US history. ${ }^{3}$ There were many challenges in the immediate aftermath, including lack of power and potable water, scarcity of food and gasoline, and lack of communication. ${ }^{3}$ Because hurricane Maria occurred at the beginning of the fall semester, all academic institutions were affected, including

Corresponding Author: Georgina Silva-Suarez, Nova Southeastern University, College of Pharmacy, 997 San Roberto St., San Juan, Puerto Rico 00926. Tel: 787-773-6570. Email: gsilvasuar@nova.edu
Nova Southeastern University College of Pharmacy's (NSU-COP's) regional campus in Puerto Rico. In the aftermath of hurricane Maria, the college was faced not only with a lack of resources as a battered island, but also with significant obstacles to completion of the 2017 fall semester.

Numerous hurricanes have impacted the mainland United States, with significant aftermath affecting academic institutions. Hurricane Ike struck Galveston Island, where the University of Texas Medical Branch is located, in 2008. They conducted a hurricane needs survey post storm and found that students experienced significant distress and faced academic performance issues. ${ }^{4}$ In 2012 , superstorm Sandy hit the coast of New Jersey, affecting Monmouth University students. Researchers found that 


\section{American Journal of Pharmaceutical Education 2020; 84 (9) Article 7808.}

headaches and loss of academic motivation affected students' grade point average, but displacement and loss of power did not have the same effect. ${ }^{5}$ The studies describing the effects of hurricane Katrina, which occurred in 2005, provide what are perhaps the most significant data on the long-term impacts of a hurricane on college students. A survey conducted among Louisiana State University students found that displaced students experienced more trauma, exposure, distress, symptoms of post-traumatic stress disorder, and symptoms of depression than those students who were not displaced. ${ }^{6}$

As a college and a distant site, one of our main priorities at the NSU-COP in Puerto Rico after hurricane Maria was to ensure our students were able to successfully complete the fall semester. The college operates mainly by broadcasting live lectures among three campuses. Because of campus closures for hurricanes Irma and Maria, students on the Puerto Rico campus were behind five weeks on the academic calendar. The campus was completely closed for 20 days after hurricane Maria, followed by a two-week period of partial closings and diminished hours of operation. Unfortunately, our campus was no longer able to catch up with the academic schedule established by the main campus. In addition, because of unstable power and lack of broadcasting capabilities, we were faced with the need to provide classes locally. A local adaptation of the curriculum was implemented. Courses were assigned based on the expertise of each local faculty member, and educators from other institutions were contacted to assist in the delivery of specialty topics. Despite this and the emotional distress faced by students and faculty and staff members, our students were able to complete their fall semester.

After this experience, we developed a study to assess the impact of hurricane Maria on first, second, third, and fourth professional year (P1, P2, P3, and P4) student pharmacists. The primary objective of this study was to assess the economic and health-related impact of hurricane Maria on NSU student pharmacists as well as to assess the hurricane's perceived impact on their academic performance. In addition, we evaluated student pharmacists' satisfaction with NSU's response to hurricane Maria.

\section{METHODS}

A 26-item survey instrument developed and administered by Watson and colleagues at the University of Texas Medical Branch was identified for use in our study. ${ }^{4}$ The primary author of that study was contacted and permission to use and adapt their survey instrument was obtained. This validated instrument included questions from six different domains: evacuation process; communication; access to services on other university campuses; financial impact, property loss, and expenses incurred; health-related matters; and post-storm access to on-campus university services. Each question was evaluated, and the 21 that were appropriate were modified as needed for inclusion in our 37-item Hurricane Impact Survey. Sixteen additional questions were created to assess the students' perception of the impact the hurricane had on their academic performance and to assess some of the local campus' responses to the crisis. All questions were closed-ended, but an open-ended comment section was included at the end of the survey. Prior to dissemination, the modified survey instrument was pre-tested by five students who assessed the survey's questions for clarity. The students' recommendations were used to modify the final survey instrument.

All student pharmacists $\geq 21$ years of age who were enrolled at the NSU-COP Puerto Rico Regional Campus in fall 2017 were invited to participate in the survey. An invitation was sent via e-mail and contained a link to the survey, which was available on the REDCap (Vanderbilt University, Nashville, TN) platform for a four-week period during May and June 2018. The email contained an explanation of the survey, its purpose, and the subject's rights. It also specified that participation was both confidential and voluntary, and that students' answers were not linked to the email. Reminders to complete the questionnaire were sent to students via e-mail on a weekly basis to stimulate participation and increase the response rate. Only one survey response per student was allowed.

Descriptive statistics included frequencies and percentages for categorical variables and means and standard deviation for continuous variables. Bivariate analysis was performed using chi square or Fisher exact tests. A multiple logistic regression model was used to determine which variables were associated with self-reported affected perception of academic performance, and to estimate the odds ratios and their $95 \%$ confidence intervals. Included in the model were gender, age, school year, and all variables that were statistically significant in the bivariate analysis. Significance was defined as an alpha $<0.05$. Data analysis was conducted using SPSS version 17. This study was evaluated by NSU's Institutional Review Board and determined to be exempt.

\section{RESULTS}

A total of 150 student pharmacists completed the survey for a response rate of $69 \%(150 / 215)$. The average age was $26(\mathrm{SD}=3.4)$ years and most $(74 \%)$ were female. Over half (52\%) of the respondents were upperclassmen (P3 and P4 students). Most sociodemographic, economic, and health-related characteristics were statistically similar 


\section{American Journal of Pharmaceutical Education 2020; 84 (9) Article 7808.}

by gender and school year. Female students were more likely than male students to report not being able to function mentally at the same level as they did before the hurricane $(41 \%$ vs $17 \%, p=.01)$. In addition, upperclassmen were more likely to report sleeping problems ( $44 \%$ vs $27 \%, p=.03)$ and fatigue $(23 \%$ vs $9 \%, p=.03)$ than underclassmen (P1 and P2 students). No other significant differences were found when data were assessed by gender and school year.

In terms of academic performance, most respondents believed or perceived that their performance had been negatively affected to some extent by their disaster experience (74\%). Almost half of the students (45\%) reported being somewhat affected, 19\% were likely affected, and only $9 \%$ were very much affected. However, $26 \%$ of the students reported not being affected at all.

Gender, age, school year, and hometown location were not significantly associated with students' self-reported negative academic performance (Table 1). A higher proportion of female students then male students believed or perceived that their academic performance had been negatively affected by the disaster experience $(77 \%$ vs $64 \%, p=.10)$. In addition, more underclassmen than upperclassmen ( $80 \%$ vs $67 \%$ ) believed or perceived that their academic performance was affected, although this difference was also not significant.

Most respondents reported suffering at least some material losses from hurricane Maria. Three students indicated having major damages to their homes. Sixty percent of the students reported having increased worry about financing their college tuition. About $78 \%$ of those who expressed financial worry also believed that their academic performance had been affected compared to $67 \%$ of those with no financial worries. However, these proportions were not statistically different. None of the variables in the economic domain were associated with students' perception of their academic performance.

In terms of health care, only a few students (7\%) reported seeking out health provider services because of the storm. They did report having difficulty with access to health care providers $(26 \%)$ and prescription medications from a pharmacy (43\%). Having difficulty with accessing health care providers was significantly associated with students' perceived poorer academic performance $(87 \%$ compared to $69 \%$ among those who did not have difficulty accessing providers, $p=.03$, Table 2).

About one third (35\%) of students reported not being able to function mentally at the same level as prior to the storm, and $16 \%$ were not able to function at the same level physically. Significantly more students $(92 \%)$ who did not feel able to function physically also believed or perceived that their academic performance had been affected compared to only $70 \%$ of those who were able to function well physically $(p=.03)$. Not feeling able to function mentally was also significantly associated with perceived negative academic performance ( $84 \%$ vs $68 \%, p=.02$ ).

The most prevalent physical symptoms reported as experienced more than usual since the hurricane included

Table 1. Student Pharmacists at a College in Puerto Rico Who Responded to a Survey to Determine Whether a Natural Disaster Had Negatively Affected Their Academic Performance

\begin{tabular}{|c|c|c|c|c|}
\hline \multirow[b]{2}{*}{ Sociodemographic Characteristics } & \multicolumn{2}{|c|}{$\begin{array}{c}\text { Academic Performance Affected } \\
\text { by the Disaster? }\end{array}$} & \multirow[b]{2}{*}{$p$ Value } & \multirow[b]{2}{*}{ Total, No. (\%) } \\
\hline & No, No. (\%) & Yes, No. (\%) & & \\
\hline \multicolumn{5}{|l|}{ Gender } \\
\hline Male & $14(35.9)$ & $25(64.1)$ & \multirow[t]{2}{*}{.10} & $39(26.0)$ \\
\hline Female & $25(22.5)$ & $86(77.5)$ & & $111(74.0)$ \\
\hline \multicolumn{5}{|l|}{ Age (years) } \\
\hline $21-25$ & $19(24.7)$ & $58(75.3)$ & \multirow[t]{2}{*}{.70} & $77(51.3)$ \\
\hline$>25$ & $20(27.4)$ & $53(72.6)$ & & $73(48.7)$ \\
\hline \multicolumn{5}{|l|}{ Year of pharmacy school } \\
\hline P1 \& P2 & $14(19.4)$ & $58(80.6)$ & \multirow{2}{*}{.08} & $72(48.0)$ \\
\hline P3 \& P4 & $25(32.1)$ & $53(67.9)$ & & $78(52.0)$ \\
\hline \multicolumn{5}{|l|}{ Hometown location } \\
\hline North & $13(26.0)$ & $37(74.0)$ & \multirow{5}{*}{.98} & $50(34.5)$ \\
\hline South & $8(29.6)$ & $19(70.4)$ & & $27(18.6)$ \\
\hline East & $9(24.3)$ & $28(75.7)$ & & $37(25.5)$ \\
\hline West & $6(31.6)$ & $13(68.4)$ & & $19(13.1)$ \\
\hline Central & $3(25.0)$ & $9(75.0)$ & & $12(8.3)$ \\
\hline Total & $39(26.0)$ & $111(74.0)$ & & $150(100.0)$ \\
\hline
\end{tabular}




\section{American Journal of Pharmaceutical Education 2020; 84 (9) Article 7808.}

Table 2. Association of Health-Related Characteristics with Perceived Academic Performance of Student Pharmacists Eight Months After Experiencing a Natural Disaster

\begin{tabular}{|c|c|c|c|c|}
\hline \multirow[b]{2}{*}{ Health-Related Characteristics } & \multicolumn{2}{|c|}{$\begin{array}{c}\text { Academic Performance Has } \\
\text { Been Negatively Affected by } \\
\text { Disaster Experience }\end{array}$} & \multirow[b]{2}{*}{$p$ Value } & \multirow[b]{2}{*}{ Total, No. (\%) } \\
\hline & No, No. (\%) & Yes, No. (\%) & & \\
\hline \multicolumn{5}{|c|}{ Had difficulties accessing health care provider } \\
\hline No & $34(30.9)$ & $76(69.1)$ & .03 & $110(73.8)$ \\
\hline Yes & $5(12.8)$ & $34(87.2)$ & & $39(26.2)$ \\
\hline \multicolumn{5}{|c|}{$\begin{array}{l}\text { Had difficulties getting any prescription drug at } \\
\text { the pharmacy }\end{array}$} \\
\hline No & $27(31.8)$ & $58(68.2)$ & .07 & $85(56.7)$ \\
\hline Yes & $12(18.5)$ & $53(81.5)$ & & $65(43.3)$ \\
\hline \multicolumn{5}{|c|}{$\begin{array}{l}\text { Able to function mentally at the same level than } \\
\text { before the hurricane }\end{array}$} \\
\hline No & $8(15.1)$ & $45(84.9)$ & .02 & $53(35.3)$ \\
\hline Yes & $31(32.0)$ & $66(68.0)$ & & $97(64.7)$ \\
\hline \multicolumn{5}{|c|}{$\begin{array}{l}\text { Able to function physically at the same level } \\
\text { than before the hurricane }\end{array}$} \\
\hline No & $2(8.0)$ & $23(92.0)$ & .03 & $25(16.7)$ \\
\hline Yes & $37(29.6)$ & $88(70.4)$ & & $125(83.3)$ \\
\hline \multicolumn{5}{|c|}{ Sleeping difficulties since the hurricane } \\
\hline No & $30(31.3)$ & $66(68.8)$ & .05 & $96(64.0)$ \\
\hline Yes & $9(16.7)$ & $45(83.3)$ & & $54(36.0)$ \\
\hline \multicolumn{5}{|c|}{$\begin{array}{l}\text { Physical symptoms experienced more than } \\
\text { usual since the hurricane } \\
\text { Headache }\end{array}$} \\
\hline No & $33(30.6)$ & $75(69.4)$ & .04 & $108(72.0)$ \\
\hline Yes & $6(14.3)$ & $36(85.7)$ & & $42(28.0)$ \\
\hline \multicolumn{5}{|l|}{ Sleeping problems } \\
\hline No & $30(31.6)$ & $65(68.4)$ & .04 & $95(63.3)$ \\
\hline Yes & $9(16.4)$ & $46(83.6)$ & & $55(36.7)$ \\
\hline \multicolumn{5}{|l|}{ Other distress } \\
\hline No & $38(29.0)$ & $93(71.0)$ & $.03^{\mathrm{a}}$ & $131(87.3)$ \\
\hline Yes & $1(5.3)$ & $18(94.7)$ & & $19(12.7)$ \\
\hline
\end{tabular}

${ }^{a}$ As determined using the Fisher exact test

sleeping problems $(36 \%)$, headaches $(28 \%)$, and backaches (17\%) (Table 2). Having headaches and having sleeping problems were significantly associated with perceived diminished academic performance. Most of the students with headaches perceived negative changes in academic performance compared to those who did not report headaches $(85 \%$ vs $69 \%, p=.04)$. Furthermore, most of those who had sleeping problems also perceived that their academic performance was affected $(83 \%$ vs $68 \%, p=.04)$.

In the multiple regression model, only school year was significantly associated with students believing or perceiving that their academic performance had been affected negatively. Underclassmen were 3.5 times more likely (95\% CI 1.3-9.4) to report negatively affected academic performance than upperclassmen after adjusting for gender, age, having difficulties accessing health care providers, not feeling able to function well physically or mentally, and having headaches, sleeping problems, or other distress.

Forty-eight students included additional comments. The following major themes emerged from the analysis of open-ended comments: lack of preparedness, gratefulness, and campus management.

Regarding lack of preparedness, some respondents (29\%) stated feeling frustrated and dissatisfied over the time it took for the college to suspend classes in order for students to prepare for the hurricane. Students also expressed feeling like the university did not have an actual plan for this event. They recommended that the Puerto Rico Campus needed to implement a protocol for future storms. Eight students from the sample relocated to the main campus in Florida after the storm. 


\section{American Journal of Pharmaceutical Education 2020; 84 (9) Article 7808.}

These eight students also indicated the need for more guidance and assistance from the administration during a crisis.

Forty percent of students reported being grateful for the local response. Because the Puerto Rico campus is a distant site, students felt that their semester would be compromised because of the event, which led to many worries. However, they expressed being thankful for the local faculty's response. Overall, the ratings students gave for the university's response to the hurricane were positive (action by main campus Florida): $43 \%$ of the students rated the university's response as excellent or good and the vast majority (81\%) gave the same ratings to the response by the faculty at the local campus (Puerto Rico). Furthermore, students also expressed gratitude for the supplies and services provided by the University after the event.

The issue that continued to frustrate students months after the storm was the lengthy reconstruction process that the campus went through. The main issues students had with the reconstruction process were the unavailability of study rooms, the lack of potable water from fountains, and the condition of the carpets, which some believed may have led to allergy problems.

In addition, students felt that the campus should have been open for more hours immediately after the storm because it was the safest and most accessible place they had for studying. Most students felt the campus was accessible one month after the storm (71\%). Despite this, over half (54\%) of the students reported that the hours of operation after campus reopening did not meet their needs.

Many students also reported having communication problems with both the main campus and the Puerto Rico campus. During the storm, $87 \%$ did not have any communication service and 26\% remained without any communication service one month after the storm. Some respondents suggested implementing student-campus communication via radio to improve in this area in future emergency situations.

\section{DISCUSSION}

This study assessed the self-reported impact of hurricane Maria on the lives of student pharmacists. A crosssectional study was used to assess academic, economic, and health-related domains. Student responses indicated that hurricane Maria had an impact in all these domains to some extent. The feedback provided by students regarding issues with communication, campus access, and contingency plans were also insightful. Perhaps the most compelling findings from this study was the negative impact the storm had on students' mental health and their perceived negative academic performance, particularly among underclassmen.
The curriculum for the underclassmen was adjusted, and some courses were rescheduled for the upcoming summer 2018 semester. Because the college had decreased students' academic load after the hurricane, we were not expecting students to report the perception of being affected academically by the storm. However, a possible explanation of their perception is that foundational topics are taught during the first academic years of our doctorate program. First-year students had only completed three weeks of classes and had not taken their first examination when the hurricane hit Puerto Rico. Similarly, second-year students were being introduced to pharmacotherapy and patient care laboratories during that semester. Therefore, these students may not have had enough time to completely adapt to the program prior to hurricane and subsequent rescheduling. Despite having classes provided by local faculty members and being given both academic and emotional support, the uncertainty of their academic progression and development of the upcoming semesters could have influenced their perception about their academic performance. Each year of pharmacy school has its own particularities, and certainly the student experience was different in 2017 given the impact of hurricane Maria. This was also evident among medical students from Puerto Rico who reported experiencing a range of difficulties, such as frustration with residency applications among fourth-year students. ${ }^{7}$ Therefore, the students' academic school year should be taken into consideration when developing a contingency plan for natural disasters.

Various studies have reported the impact of natural disasters on students' academic performance. Watson and colleagues found that $47 \%(n=244)$ of the students they studied reported that Hurricane Ike negatively affected their academic performance. Doyle and colleagues (2017) found that headaches and loss of academic motivation were factors associated with a reduction in students' GPA $(p<.05)$. We had similar findings in terms of students reporting headaches and declines in mental and physical function, and the association of these with poorer academic performance. Therefore, these symptoms must be evaluated and cared for in the aftermath of natural disasters.

A viewpoint published in the JAMA Internal Medicine reported that Puerto Rican medical students had similar troublesome experiences after hurricane Maria. ${ }^{7}$ The students struggled to study for courses, rotations, and board examinations. They faced similar communication problems and unstable power, and they had missed three weeks of academic activities by the time classes resumed. ${ }^{7}$ We faced a more complex situation because we are a distant learning site that relies on advanced 


\section{American Journal of Pharmaceutical Education 2020; 84 (9) Article 7808.}

technology to conduct classes and the daily operations of the college. Because of hurricane Irma, our campus was closed for two weeks in early September and after hurricane Maria, and remained closed to students for three additional weeks. This placed our students at a disadvantage compared to students on our campuses on the mainland. Despite the hardships of the situation that we were facing at the time, classes resumed on October 16, 2017. Significant adjustments were made to the curriculum and we used local faculty members, personnel, and resources to make it possible for our students to complete the semester.

According to the official end of the year academic report, our students' perception of their academic performance did not match their actual academic performance. Despite that $45 \%$ and $28 \%$ of the students reported being somewhat or very much likely affected by the hurricane their ability to comply with academic requirements was not affected after the hurricane. In the fall 2017 semester, all student pharmacists at NSU's Puerto Rico Regional Campus passed their courses, and in winter 2018 almost all students successfully completed the semester (two students failed one course). The adjustments made to the curriculum, local adaptations, and course rescheduling all could have influenced the positive performance of our students.

During the semester in which hurricane Maria occurred, the successful progression rate of underclassmen (P1 and P2 students) was 98\%. For P3 students, the progression rate was $89 \%$, and for $\mathrm{P} 4$ students, it was $100 \%$. By the winter semester, all our underclassmen students had returned and $91 \%$ of P2 students were on track for enrolling in fourth-year advanced pharmacy practice experiences.

As an academic institution and a distant learning site, it was important for us to evaluate our response to this hurricane and make any necessary changes prior to future natural disasters. There was a campus Emergency and Continuity Plan; however, it was not widely known by our students. In addition, there was not a standard policy on when to close or not close the campus in the event of an approaching hurricane. The feedback obtained from our students was instrumental in identifying the main areas in which improvement was needed: communication, campus closure, campus opening hours, and relocation guidance. Furthermore, because of the association of mental and physical health with students' self-reported academic performance, services to address mental health should made available. These results will be used to guide an appropriate response in the event of future natural disasters. Some of the improvements have already been implemented or are in progress in the areas of communication, campus closure, mental health, and preparedness.
To address the issue of communication with the main campus in Florida, the NSU College of Pharmacy now has satellite phones available for administrators on each campus. This should facilitate communication among campuses during future events as all locations are at risk of hurricanes. In response to student concerns regarding the delayed closure of the campus, the university has adopted a policy to close the regional campus as soon as the government of Puerto Rico orders closures of other academic facilities.

The unmet mental health needs of our students were a significant finding in our study. The university does not have mental health professionals located on distant campuses; however, mental health services for all campuses are available to students through teleconference and web-assisted technologies. Unfortunately, because of the lack of internet and communication capabilities in the aftermath of the storm, these services were unavailable to students on the Puerto Rico campus. In response to this, the semester following the storm, the university brought mental health services' personnel to our campus in Puerto Rico and conducted group orientations about the services available and how to access them remotely. However, these resources did not seem sufficient for students needing one-to-one or long-term services. In future events, identifying local providers or bringing personnel in to provide these services to the island in the immediate aftermath should be considered.

In response to the experience of hurricane Maria, the regional campus disaster plan was reevaluated, amended, and aligned with the university-wide response plan. This plan facilitates for unit and subunits, such as the College of Pharmacy, to develop a specific plan to address programmatic and academic particularities. The college of pharmacy is in the process of creating this plan. Other colleges of pharmacy have adopted similar plans. ${ }^{9}$ Specific topics that need to be addressed in this plan include communication and student relocation. One of the greatest obstacles we faced on the island was the complete collapse of communications and power. ${ }^{10}$ The only available communication avenue for days after the storm was the radio. ${ }^{10}$ Hence, this and other platforms for keeping students informed should be included in our college's plan. The inability to communicate created anxiety among students about how they would complete their courses and clinical rotations for the semester. Because of this, some students relocated to campuses in Florida. As a college, however, we did not have an established procedure for such a scenario. At the time, relocation had been an option only in special circumstances upon approval of the college dean. We have since learned that relocation of students to another campus 


\section{American Journal of Pharmaceutical Education 2020; 84 (9) Article 7808.}

after a natural disaster is common; however, adjustments at the receiving school and to academic services have to be made to meet the needs and assist those who relocate. ${ }^{11}$ Therefore, a relocation protocol should be created to guide students and faculty members during this process. It should provide guidance in terms of appropriate time limits for relocation and specific guidelines for administrators at each campus to receive relocated students. Following the example of other universities, we now plan to provide hurricane preparedness information to students during orientation week. ${ }^{4}$ This information will be redistributed each academic year and will contain guidance based on the issues faced during hurricane Maria.

The overarching goal of this paper was to reflect on this life-changing experience, identify lessons learned as a college, and improve preparedness plans for future events. Many of the lessons we learned are very specific to our campus being a distant learning site. Therefore, it should be of interest and serve as guidance for other schools with distant site campuses who are in the process of creating or revising a natural disaster response.

Limitations of this study were the survey was conducted at the end of the academic year and students were transitioning from one academic year to the other; the survey was launched 8 months after the storm, and this could have potentially diminished the true impact of the hurricane in the students' lives; and since the investigators were also faculty of the respondents, the investigators were susceptible to the social desirability bias.

\section{CONCLUSION}

Hurricane Maria had a significant impact on the lives of student pharmacists in Puerto Rico. This resulted in students' self-reported negative perception of their academic performance, especially among those with healthrelated issues and among underclassmen. Areas identified for improvement based on student responses included: communication, campus closure, campus opening hours, and relocation guidance. Each institution is unique and should conduct self-evaluations to improve their response to natural disasters. For students in Puerto Rico, hurricane Maria will always be remembered. Their resilience has motivated us as a college to learn from this experience and adapt in the face of adversity.

\section{REFERENCES}

1. National Oceanic and Atmospheric Administration. Major Hurricane Maria - September 20, 2017. https://www.weather.gov/sju/ maria2017. Accessed March 15, 2018.

2. Fritz A. Puerto Rico has a long history with tropical storms. None of them were like Hurricane Maria. Washington Post. September 19, 2017. https:/www.washingtonpost.com/news/capital-weather-gang/ wp/2017/09/19/puerto-rico-has-a-long-history-with-tropical-stormsnone-of-them-were-like-hurricane-maria/. Accessed March 18, 2018. 3. Pasch RJ, Penny AB, Berg R. National Hurricane Center Tropical Cyclone Report: Hurricane Maria. https://www.nhc.noaa.gov/data/ tcr/AL152017Maria.pdf. Published February 2019. Accessed May 10, 2019.

4. Watson PG, Loffredo VJ, McKee JC. When a natural disaster occurs: lessons learned in meeting students' needs. J Prof Nurs. 2011; 27(6):362-369.

5. Doyle MD, Lockwood B, Comiskey JG. Superstorm Sandy and the academic achievement of university students. Disasters. 2017; 41(4):748-763.

6. Davis III TE, Grills-Taquechel AE, Ollendick TH. The psychological impact from Hurricane Katrina: effects of displacement and trauma exposure on university students. Behav Ther. 2010; 41(3):340-349.

7. Quiñones-Rivera A, Rubin A. Medical students in Puerto Rico after Hurricane Maria. JAMA Intern Med. 2018;178(5):603-604. 8. Yordan-Lopez N, Hernandez-Suarez DF, Marrero-Ortiz W, Marshall-Perez L, Lopez-Candales A. Challenges and opportunities after Hurricane Maria: University of Puerto Rico medical students' perspectives. J Grad Med Educ. 2018;10(4):382-384.

9. Auburn University Harrison School of Pharmacy. HurricaneDisaster Plan. 2015. https://www.auburn.edu/academic/pharmacy/ about/pp/hurricane-disaster-plan.pdf. Accessed May 20, 2018. 10. Zorrilla CD. The view from Puerto Rico - Hurricane Maria and its aftermath. N Engl J Med. 2017;377(19):1801-1803.

11. Meléndez E, Hinojosa J, Román N. Post-Hurricane Maria exodus from Puerto Rico and school enrollment in Florida. Center for Puerto Rican Studies. December 2017. https://centropr.hunter.cuny.edu/ sites/default/files/CentroReport-RB2017-02-POST-MARIA-FL-PREXODUS\%20\%281\%29.pdf. Accessed March 8, 2018. 